University of Nebraska - Lincoln

DigitalCommons@University of Nebraska - Lincoln

Sociology Department, Faculty Publications

Sociology, Department of

2016

Rural and Urban Communities

Emily Kazyak

University of Nebraska-Lincoln, ekazyak2@unl.edu

Follow this and additional works at: https://digitalcommons.unl.edu/sociologyfacpub

Part of the Family, Life Course, and Society Commons, and the Social Psychology and Interaction

Commons

Kazyak, Emily, "Rural and Urban Communities" (2016). Sociology Department, Faculty Publications. 733. https://digitalcommons.unl.edu/sociologyfacpub/733

This Article is brought to you for free and open access by the Sociology, Department of at DigitalCommons@University of Nebraska - Lincoln. It has been accepted for inclusion in Sociology Department, Faculty Publications by an authorized administrator of DigitalCommons@University of Nebraska - Lincoln. 


\section{Rural and Urban Communities}

This entry describes how LGBTQ individuals in rural areas have different experiences from those of LGBTQ individuals in urban areas. It outlines how understandings about cities and small towns have been intertwined with understandings about LGBTQ identities as well as what current demographic data show with regard to where LGBTQ people live in the United States. Then the entry details LGBTQ identities and communities in urban contexts. It ends by describing LGBTQ identities and communities in rural contexts. Throughout, attention is paid to the diversity of experiences within each context.

\section{Geography and LGBTQ Identities and Communities}

LGBTQ identities have been associated with urban spaces. Early work in LGBTQ studies focused exclusively on individuals and communities in cities and documented how subcultures developed in places such as New York and San Francisco. It is assumed that such urban areas continue to afford individuals the freedom to express lesbian, gay, bisexual, and queer (LGBQ) sexualities and transgender gender identities. Embedded in this assumption is that the opposite is true in rural areas. LGBTQ individuals in small towns are assumed to hide their sexual or gender identity or to face hostility if they do express it. It is assumed, therefore, that rural LGBTQ people will migrate to a city.

Certainly for some LGBTQ individuals, these assumptions match their experiences. Scholarship has demonstrated the migration of LGBTQ people from rural to urban locales and the importance of neighborhoods in cities that are home to a large number of LGBTQ people (or visible gay neighborhoods). Yet demographic data suggest that LGBTQ people are now living in a range of contexts-not only in visible gay neighborhoods in cities. In fact LGBTQ individuals live in 99\%

Published in The SAGE Encyclopedia of LGBTQ Studies, edited by Abbie Goldberg (Thousand Oaks, CA: SAGE Publications, 2016), pp. 973-976. 
of U.S. counties: The number of same-sex couples in rural areas has increased. Likewise, the concentration of same-sex couples in urban neighborhoods traditionally home to a large number of LGBTQ people has declined. These patterns are attributed to a number of factors, including gentrification processes in cities whereby many LGBTQ people can no longer afford to live in urban areas. These patterns also reflect the increasing societal acceptance of LGBTQ people. Rather than needing to seek out certain urban neighborhoods, LGBTQ people may increasingly feel comfortable in nonurban communities.

\section{Urban Communities}

Starting in the early 2oth century, individuals have found that urban spaces allowed them freedom to express LGBTQ genders and sexualities. Bars in particular were important for identity and community development. Bars allowed people to meet each other, to develop certain aesthetics in terms of expressing identity such as drag, and to organize politically. Research on contemporary urban communities indicates that visible gay neighborhoods exist in many cities. These neighborhoods are home to business and community organizations that cater to LGBTQ individuals. These neighborhoods are often visibly marked by rainbow flags flying on streets, for instance, and are sites where gay pride events occur. Along with the existence of such visible urban gay neighborhoods, research also indicates that there is diversity within cities with regard to how LGBTQ identities are expressed and how LGBTQ communities are experienced.

First, there is diversity among urban LGBTQ people's experiences insofar as not all LGBTQ people live in visible gay neighborhoods. For instance, Black LGBTQ people in Los Angeles and New York City are more likely to live in predominantly Black neighborhoods as opposed to gay neighborhoods. For some, their social lives and communities are thus more organized around friendship networks and private house parties, for instance, rather than through visible institutions like bars in gay neighborhoods, which are predominantly White. Additionally, Black and Latina/o LGBTQ individuals develop their own subcultures distinct from those of White LGBTQ individuals in many cities.

Further, there are divisions along race, class, and gender lines in urban LGBTQ communities, despite the assumption that the city is 
the place to find and build a community around a shared marginalized sexual or gender identity. Those most likely to be living in urban visible gay neighborhoods are often White, middle- and upper-class, gay cisgender (cisgender, meaning not transgender) men. Transgender individuals and sexual minorities who are bisexual, racial minorities, women, or people of lower socioeconomic class may be less likely to live in or feel a sense of belonging in visible gay neighborhoods.

The demographic makeup of visible gay neighborhoods has been exacerbated by gentrification. As working-class neighborhoods transition to middle- and upper-class neighborhoods, poorer LGBTQ individuals, including women, people of color, and transgender people, can no longer afford to live in visible gay neighborhoods. Such realities mean that the experience of urban spaces are raced, classed, and gendered. The assumption that cities are utopic for LGBTQ people ignores the violence that LGBTQ people can experience in urban locales. Nonetheless, visible gay neighborhoods continue to be important spaces for many LGBTQ individuals, even if they are not actually residents of these neighborhoods.

\section{Rural Communities}

Increasingly, scholars in LGBTQ studies are focusing on rural areas. With this focus, scholars not only remedy the bias of prior literature that solely focused on urban areas and show that people with diverse sexualities and genders have always lived in rural areas but also address the increasing geographical diversity of LGBTQ individuals.

Some historical work underscores that just as urban sexual subcultures were emerging in the early 2oth century, similar processes were occurring in rural contexts. Likewise, LGBTQ activism in the mid- to late 2 oth century, including radical faerie groups and the lesbian land movement, sought to create welcoming spaces for LGBTQ people in rural contexts. For such groups, a rural environment was imagined as an escape from an urban lifestyle and as a place to more freely express non-normative genders and sexualities. Further, there are some small towns such as Ithaca, New York, or Northampton, Massachusetts, that have a reputation for being LGBTQ-friendly and have a large LGBTQ population. Thus, despite assumptions that all rural areas are alike and anti-LGBTQ, this is not the case. 
Yet not all LGBTQ individuals living in rural areas are connected to such intentional or LGBTQ-friendly communities. The experiences of these individuals are diverse. Some may experience same-sex desires or have same-sex sexual experiences but not adopt a lesbian, gay, bisexual, or queer (LGBQ) identity. Others may adopt an LGBQ identity and find that although there are many elements they enjoy about rural life, including a slower pace, a connection to the outdoors, and close relationships with family and friends, they also face barriers with regard to being isolated, not feeling comfortable expressing their gender or sexual identity, and not feeling connected to an LGBTQ community. These barriers can be exacerbated for individuals living in certain areas where religious teachings that oppose LGBTQ sexualities and genders are central to the community. Alternatively, others may adopt an LGBTQ identity and report being out, visible, and accepted in small towns. In fact, compared to their urban counterparts, sexual minorities in small towns are not more likely to be closeted and report higher levels of well-being.

Some LGBQ individuals in small towns understand their sexual identity to be uniquely rural and to be distinct from urban LGBQ identities. For instance, their understandings about what it means to be out and visible are predicated on their characterization of small towns as exuding a close-knit, everybody-knows-everybody atmosphere. This atmosphere sustains their sense of being visible by being seen around town with a same-sex partner or their sense of being out in the community, since knowledge of their sexuality travels fast around town given how interconnected people are. They see this way of expressing LGBQ identities to be distinct from what they imagine happens in cities, where people might be active in LGBQ communities, or fly rainbow flags, or go to LGBQ bars and pride parades. Yet other LGBQ individuals, particularly young ones, do not see such expressions to be incompatible with rural life and, for instance, as Mary Gray shows, are active in local pride groups or do drag shows at the local Walmart.

Further, LGBTQ people's experiences of rural communities also differ by race and class. Being accepted as an LGBTQ individual is predicated on having ties to the community and embracing small-town ways of life. Who is able to be seen as legitimately belonging in a small town is racialized insofar as rural and White are conflated and urban and racial diversity are conflated; namely it is White LGBTQ 
individuals who are seen as belonging. ln terms of class, rural (in contrast to urban) is understood as inhabited by poor or lower-class people in popular imaginations. Some rural LGBTQ people distance themselves from urban people, whom they see as higher-class and whom they in turn devalue, including urban LGBTQ people. Likewise, some rural LGBTQ people live in poverty. Yet class differences also exist within rural communities, such that LGBTQ people with class privilege meet greater acceptance and tolerance with regard to their LGBTQ identity.

In sum, LGBTQ studies scholars have unearthed a rich history of communities where LGBTQ genders and sexualities flourish in both urban and rural communities. Whereas small towns and LGBTQ identities were once assumed to be incompatible, emerging work illustrates how many LGBTQ individuals are out and accepted in rural areas. Importantly, scholars also address the diversity of experiences for LGBTQ individuals in both urban and rural contexts.

\section{Emily Kazyak}

University of Nebraska-Lincoln

\section{Further Reading}

Abelson, M. (2015). Gendered violence and intersectionality in the everyday experiences of transgender men. In C. M. Renzetti \& R. Kennedy-Bergen (Eds.), Understanding of diversity (pp. 53-64). Upper Saddle River. NJ: Pearson Education.

Bailey, M. (2013). Butch Queens in pumps: Gender, performance and ballroom culture in Detroit. Ann Arbor: University of Michigan Press.

Barton, B. (2012). Pray tbe gay away. New York: New York University Press.

Chauncey, G. (1994). Gay New York: Gender, urban culture and the making of the gay male underworld 1890-1940. New York. NY: Basic Books.

Ghaziani, A. (2014). There goes the gayborhood? Princeton. NJ: Princton University Press.

Gray, M. L (2009). Out in the country: Youth, media, and queer visibility in Rural America. New York: New York University Press.

Greene, T. (2014). Gay neighborhoods and the rights of the vicarious citizen. City \& Community, 13, 99-118.

Halberstam, J. (2005). In a queer time and place: Transgender bodies, subcultural lives. New York: New York University Press.

Johnson, C. R. (2013). Just queer folks: Gender and sexuality in rural America. Philadephia. PA: Temple University Press. 
Johnson, P. E. (2008). Sweet tea: Black gay men of the South. Chapel Hill: University of North Carolina Press.

Kazyak, E. (2011). Disrupting cultural selves: Constructing gay and lesbian identities in rural locales. Qualitative Sociology, 34, 561-581.

Kazyak, E. (2012.). Midwest or lesbian? Gender, rurality, and sexuality. Gender \& Society, 26, 825-848.

Kennedy, E. L. \& Davis. M. (1993). Boots of leather, slippers of gold: The history of a lesbian community. New York, NY: Penguin Books.

Moore, M. (2010). Black and gay in L.A.: The relationships Black lesbians and gay men have with their racial and religious communities. In D. Hunt \& A. Ramon (Eds.). Black Los Angeles: American dreams and racial realities (pp. 188-212). New York: New York University Press.

Oswald, R. F. \& Culton, L. (2003). Under the rainbow: Rural gay life and its relevance for family providers. Family Relations, 52, 72-81.

Rupp. L. \& Tayloe, V. (2003). Drag queens at the 801 Cabaret. Chicago, IL: University of Chicago Press.

Swank, E. Frost, D. \& Fahs, B. (2012). Rural location and exposure to minority stress among sexual minorities. Psychology \& Sexuality, 3, 226-243.

Weston. K. (1995). Get thee to a big city: Sexual imaginary and the great gay migration. GLQ, 2, 253-277.

Wienke, C., \& Hill, G. (2013). Does place of residence matter? Rural-urban differences and the wellbeing of gay men and lesbians. Journal of Homosexuality, 6o, 1256-1279. 